ESJ Social Sciences

\title{
Transitioning to the New Normal in Education: A Case Study of Chinese School Leaders in the Philippines
}

\author{
Gina Pecson \\ Philippine Christian Gospel School, Cebu City, Philippines \\ Angeline Pogoy \\ Cebu Normal University, Cebu City, Philippines
}

Doi:10.19044/esj.2021.v17n35p130

Submitted: 06 August 2021

Accepted: 06 October 2021

Published: 31 October 2021
Copyright 2021 Author(s)

Under Creative Commons BY-NC-ND

4.0 OPEN ACCESS

Cite As:

Pecson G. \& Pogoy A. (2021). Transitioning to the New Normal in Education: A Case Study of Chinese School Leaders in the Philippines. European Scientific Journal, ESJ, 17 (35), 130. https://doi.org/10.19044/esj.2021.v17n35p130

\begin{abstract}
This paper focuses on exploring the different changing roles and leadership practices of the two Chinese private school leaders in basic education in the new normal with its challenges and opportunities. This case study approach was done through semi-structured interviews and supplemented with documents including e-mails, written reports, meeting notes, and other related documents used for triangulation to strengthen the credibility of outcomes. It also enables different interpretations and meanings to be included in the data analysis. The findings revealed that the two Chinese private school leaders have adapted the four leadership practices successfully in their respective institutions, as they went through the process of restructuring the teaching and learning in the new normal where challenges and opportunities were enormous. These four leadership practices were Situational Leadership, Instructional Leadership, Benchmarking Leadership, and Distributed Leadership that school leaders had to modify and adapt depending on the situations to accommodate an ever-changing environment during and after the COVID-19 pandemic. The adaptability of different changing roles and leadership practices depending on its situations are the essential qualities of school leaders to rise above the circumstances and thrive in crisis during and after the COVID-19 pandemic.
\end{abstract}

Keywords: Chinese private school leaders, new normal, leadership practices 


\section{Introduction}

Chinese private school leaders are considered as "endangered species" because they are scarce and insufficient for demand. This makes their administrative and instructional leadership as valuable as precious gems. Their roles and functions are crucial in planning, organizing, leading, and controlling the whole organization to ensure student academic success and enhance teachers' quality (Day \& Sammons, 2013). Thus, the COVID-19 pandemic has brought enormously increasing demands in pivoting their leadership styles and skills in such a crisis (Fernandez \& Shaw, 2020).

School leadership within Organization for Economic Cooperation and Development (OECD) countries like Australia, Canada, Finland, Korea, New Zealand, United Kingdom, and the United States has changed significantly (Pont, Nusche \& Moorman, 2008). They are confronted with an everincreasing set of demands (Pont et al., 2008) due to the increased levels of competition in economic globalization and technology for the sake of improvement in education (United Nations Educational, Scientific and Cultural Organization UNESCO, 2016). This prepares the $21^{\text {st }}$-century learners with the needed knowledge and skills in a fast-changing environment (Day \& Sammons, 2013). Ironically, we are living in this generation with a $21^{\text {st }}$ century school but still delivering a $20^{\text {th }}$-century curriculum (HayesJacobs, 2014 as cited in Zhang, Bohley \& Wheeler, 2017). Certainly, their roles are crucial in the effectiveness of quality education (Laila, 2015) in this rapid change of globalization and digitalization (Litz, 2011). However, many countries put much attention in investing their resources for teacher training, learning materials, equipment, and facilities. Paradoxically, very few have thought of investing on the potential of school leadership as a means of improving quality education (UNESCO, 2016). Therefore, it is critically important to develop competent school leaders with a global perspective to understand and analyze other countries' educational systems to partner and learn from them (Zhang et al., 2017).

Specifically, school leadership in the Philippines Region $\mathrm{X}$ has exemplified four leadership practices such as managerial, participative, moral, and instructional leadership (Pasia, 2019). All these have played multiple roles in facilitating transition efforts. However, Cruz, Villena, Navarro, Belecina, and Garvida (2016) revealed in their study that even though school leaders in Region IV-A have a satisfactory level in their managerial performance, there are some weaknesses that needs to be enhanced. Likewise, Hechanova, Caringal-Go, and Magsaysay (2018) showed in the study that it is important to understand change in leadership scheme as a result of also managing change in organizations. It was also suggested that there is no one-size-fits-all approach in leadership. In addition, the Philippine public and private school 
leaders must be skillful in engaging with the people to achieve organizational goals (Hechanova et al., 2018).

Furthermore, the roles of school leaders are intensified in fulfilling their responsibilities in instructional and administrative management as they experienced during the COVID-19 pandemic. This has brought undisputable chaos in the education system which has led to 1.6 billion learners out of school during this crisis (UNESCO, 2020 as cited in Harris \& Jones, 2020). Drastically, it has changed the world's education system by restructuring teaching and learning with the use of different modalities (Netolicky, 2020). The urgent decision for an online class or blended learning brought stress to different stakeholders who may require varied changes in strategies, styles, and attitudes (Heifetz \& Laurie, 2001 as cited in Fernandez \& Shaw, 2020). Likewise, parent involvement plays a critical role in the success of students in the new normal education (Toure \& Guoxin, 2016). Having known these facts, school leaders must act swiftly (Derksen, 2020 as cited in Netolicky, 2020) with strategic planning and management taken in a time of crisis (Netolicky, 2020 as cited in Harris \& Jones, 2020). This has become very challenging on their part for having less than three to four months (March to July) to strategize before the opening of the school year (2020-2021).

As a result, the roles of school leaders are so complex in dealing with human relations management, administrative tasks, and tough decisionmaking as they are often faced with conflicting stakeholder views (Netolicky, 2020). In such a crisis, school leaders need to connect to learn from others as well as learn to connect with others (Delahunty, 2018). They also need to set the direction of the school as they plan, implement, and evaluate crossfunctional decisions to achieve its organizational objectives and maximize the right people with their potentials (Athapaththu, 2016). The communication channel should be properly coordinated. Henceforth, effective leaders who use different leadership practices may affect the organizational effectiveness or performances, and influence followers to achieve the desired goals and to reduce attrition rate (Nanjundeswaraswamy \& Swamy, 2014).

To date, research studies were conducted only among the public and private schools. However, there was no related literature or study found about school leaders among the Chinese private schools in the Philippines. Notably, the most obvious difference between a regular Philippine private or public learning institutions from a Chinese learning institution here in the Philippines is the teaching of the Chinese language as part of the curriculum to preserve its Chinese traditions, culture, and heritage. This follows the rules of class hours set by the Philippine higher education committee, i.e., teaching six hours per week (Yang, 2014).

This study aimed to explore the leadership practices of the two Chinese private schools as they went through the process of restructuring the teaching 
and learning in the new normal with its challenges and opportunities. Specifically, this study sought to answer the following research questions: (1) How did the Chinese private school leaders in basic education navigate during the process of restructuring the teaching and learning in the new normal? (2) How did they respond to issues, concerns, gaps, and challenges before, during, and after the restructuring of the teaching and learning in the new normal? (3) What are some opportunities brought by the restructuring of the teaching and learning in the new normal? (4) How did all these things affect the school community personally and professionally during and after the COVID-19 pandemic?

\section{Research Methodology}

A case study is utilized as an ideal in-depth understanding of research design that occurs within the data (Merriam, 1998 as cited in Zainal, 2007). This study utilized a very limited number of individuals as the subjects because the research requires a close examination of people, topics, and issues (Hays, 2004 as cited in Armfield, 2007). Furthermore, it was very appropriate in this study because little research has been made (Merriam, 1998 as cited in Zainal, 2007) especially among the Chinese private schools in the Philippines. The objectives set was to describe the data as they occur and it must be written in a narrative form (McDonough \& McDonough, 1997 as cited in Zainal, 2007). There are six steps to follow in doing a case study design. First, determine the research question and generally starts with how or why. Second, choose the case and state how the data is to be gathered. Third, prepare to collect the data. Fourth, collect the data in the field and organize them. Fifth, analyze the data. Then, lastly, report the data (Glen, 2015).

\subsection{Research Environment}

This study was conducted in two different private schools across the Philippines. The first Chinese private school was from the island of the Visayas with a total of 730 students and a total of 80 faculty and staff members located in Cebu City. The second one was from the island of Mindanao with a total of 654 students and a total of 66 faculty and staff members located in General Santos City. These two schools were chosen based on the following criteria: enrolled students with majority from Chinese middle-class to affluent families, accredited schools, good quality of education, medium scale of population size, good location and proximity to the city.

\subsection{Research Participants}

The participants in this study were both female and seasoned Chinese Private School Leaders who have been serving as school leaders for two decades and more. 


\subsection{Research Sampling}

Purposive sampling was used in this study where in-depth investigation and deeper appreciation of the cases was done by not making a sweep statement of the findings (Ishak, Bakar \& Yazid, 2014). Interviews were conducted to the selected participants due to their qualities, extreme time, and cost-effectiveness to enhance the study's effectiveness (Etikan, Musa \& Alkassim, 2016).

\subsection{Research Instrument}

The researchers were the main instrument of this study, as they played the crucial role during interviews and the interpretative process as pointed out by Pezalla, Pettigrew, and Miller-Day (Xu \& Storr, 2012). As data were collected, data were also questioned and informed commentaries were provided (Morse, 1998 as cited in Xu \& Storr, 2012).

\subsection{Data Gathering}

This case study was done through semi-structured interviews and supplemented with documents including e-mails, written reports, meeting notes, and other documents which may serve as triangulation to strengthen the credibility of outcomes, and enable different interpretations and meanings to be included in the data analysis (Flicker, 2014 as cited in Shanks \& Bekmamedova, 2018). Permission was secured from the school leaders before the conduct of the interview with transmittal letters sent through email to seek permission to conduct the study. Interview guide questions and informed consent were also sent to the participants through email.

\subsection{Data Collection}

Semi-structured interviews were conducted with the two participants through Zoom Meeting to provide richer and deeper insights. Furthermore, this is to gather multiple data sources to enhance data credibility (Yin, 2003 as cited in Baxter \& Jack, 2008) and to add richness, breadth, and depth to data collection (Yin, 2009). These sources that served as triangulation like documentation and archival records were done to crosscheck the trustworthiness of the information in this study (Rahim \& Daud, 2015 as cited in Shoaib, Bahaudin \& Mujtaba, 2016). Data storage may include audio recordings, note-taking, filing of hard copy documentation, interview transcriptions, and other documents related to this study were stored electronically.

\subsection{Data Analysis}

Coding is vital in the process of identifying concepts, similarities, and conceptual reoccurrences in the data because it is the linkage between data 
generation and theory development (Chun, Birks \& Francis, 2019). Transcription of the interview was done in its verbatim form and codes were constructed about the concepts related to this study. Themes were formulated through the progress of line-by-line coding and integration of subcategories through constant comparison, modification, and analysis of concepts.

In this study, data were synthesized and significant statements were trimmed down before the interpretation without compromising the data as pointed out by Sharan (2009) and Harrison, Birks, Franklin, and Mills (2017). This is to increase the credibility of the interpretation (Merriam, 1998 as cited by Yazan, 2015) and the rigor of the study (Harrison et al., 2017).

\subsection{Rigor and Trustworthiness}

Trustworthiness or rigor of qualitative research and transparency of the conduct of the study is crucial to the usefulness and integrity of the findings (Connelly, 2016). This is because it refers to the degree of confidence in data, interpretation, and methods used to ensure the quality of a study (Pilot \& Beck, 2014 as cited in Connelly, 2014). Rigor was done carefully and accurately in the process of data transcription, analysis, and interpretation. Likewise, triangulation through other data sources like documentation, archival records such as meeting minutes, written reports, and other documents related to this study were also done to crosscheck the trustworthiness of the information in this study (Rahim \& Daud, 2015 as cited in Shoaib et al., 2016). Hence, whatever the results may be, it should remain as it is so that the value, consistency, truthfulness, and neutrality will be ensured (Cypress, 2017). Thus, this shows the trustworthiness of this study.

\subsection{Ethical Considerations}

Informed consent was explained and given to each participant before the interview began. Each participant was given a pseudonym. Names in transcripts were changed or deleted. Field notes with their pseudonyms were kept separately and other identifying information was kept confidential. Ethical considerations are very critical to any research, and proper steps must be taken to ensure that participants are fully aware of their participation and role (Skordis-Worrall, Haghparast-Bidgoli, Batura \& Hughes, 2015). To safeguard the participants' rights and firms' information, the names of the firms in the report were not included to protect the privacy of the individuals and company.

\section{Results and Discussions}

The analysis of transcripts revealed four major themes that best describe the experiences of the informants. Each theme was labeled in a phrase 
deduced from the formulated meanings of the responses of the informants. The four major themes as derived from the present set of transcripts were as follows:

\subsection{THEME 1. Adapting with the Current Change}

From the very beginning of the interviews, it was highlighted that both school leaders admitted that they must embrace change as revealed by the following statements:

Participant 1

Change is constant which means that we have to expect that change is occurring continuously. As early as April, the decision for the online class was made already. Also, health protocols and a skeletal workforce are strictly followed in school. For this school year, we are after the efficiency of the teachers even if they work from home.

Participant 2

If it is not mandated by the government, we go face-to-face but if it's really mandated, we have no choice. That's why I really told the teachers to explore on their own first because we cannot meet together. They should study whatever apps that are available online, and then we'll just decide later on what kind of apps we're going to use on our teaching if the government would mandate the online teaching. Teachers may work in school if they prefer to do so, except during the holidays.

Both school leaders have experienced when they were caught in such an unfavorable time (Harris \& Jones, 2020) where they do not have any choice but to wait for the announcement from the government about health protocols, school calendar for SY 2020-2021 from the Department of Education, and other procedures. Admittedly, they knew that this change was so sudden and had no choice but to use social media for communication when lockdown or strict quarantine was implemented. In such a situation, these school leaders were quick to think, plan, and respond according to the current needs of the organization and employees. They both have shown characteristics of flexibility and adaptability based on the existing work environment and the needs of an organization (Yukl \& Mahsud, 2010; McCleskey, 2014). This type of leadership is called the situational leadership approach which was developed by Hersey and Blanchard in 1982. It states that leaders should be flexible enough to change their style to fit the context (Lynch, 2015).

Therefore, both participants have exemplified their situational leadership style to suit the requirements of the organization. Both participants believed that the efficiency of the teachers is what makes it important now even if they work from home. 


\subsection{THEME 2. Building Up People}

Amidst the immense responsibilities of the school leaders, both participants put much effort into engaging themselves with the instructional programs and the professional growth of the teachers. By working directly with their principals or coordinators, these participants were also able to monitor, evaluate, and develop teacher's performances and skills through mentoring and coaching. These are their statements:

Participant 1

There were numerous free webinars from different publishing companies about online teaching and learning. Teachers were asked to join the webinars in as much as they can to learn some skills in preparation for the online class.

As early as May, there were numerous times of instructional coaching between the department coordinator and teachers at the same time. There were also peer mentoring among the teachers for those trial periods of delivering their lessons using zoom meetings or google meet, while we were still exploring some apps and LMS.

Participant 2

I requested everyone to start exploring the apps. When it was around May, the government informed us that the quarantine would be lifted, so we decide to report for work in June and we assigned the subject coordinators in-service training. Assigned also was a workshop for the different apps that were available so that the teachers will be familiar with all the different apps.

Additional pieces of training were given to those who were not very techy. We had a seminar on how to prepare online tests...we had training on how to prepare lessons and strategies. So, more focus, more time was given to the training of the Chinese teachers.

With the sudden shift to online distance learning, school leaders highly encouraged the teachers to join numerous webinars during the quarantine period in preparation for the online class. The internet gives teachers the vast opportunity to explore many educational applications to develop their $21^{\text {st }}$ century skills in communication and critical thinking ((Kakampoura, Katsadoros, Nounanaki \& Kolokythas, 2017). However, there are many times that instructional supervision is not effective, and this could be due to busyness or lack of theoretical knowledge on how to conduct instructional help for teachers (Zepeda, 2012). As an instructional leader, the principal must be knowledgeable in the curriculum, methods of instruction, and able to support teachers (Blase \& Blase, 2004 as cited in Wilson, 2012). They must be competent in formulating educational policies and conducting in-house workshops (Blase, 1987 as cited in Hussin \& Abri, 2015). Unfortunately, 
many teachers are not satisfied with the instructional leadership of their school heads due to some supervisory issues like inefficiency, incompetence, and lack of interest (Darishah, Daud \& Fauzee, 2017). It was also reported that teachers felt uneasy during supervision as if they are engaged in cold war tactics where neither side trusts the other (Blumberg, 1980 as cited in Duffy, 2017). Therefore, the role of school leaders is critical in creating a school culture void of fear or ridicule to give constant support, encouragement, and motivation towards teachers (Alzoraiki, Rahman \& Mutalib, 2018 as cited in Baptiste, 2019).

On the contrary, both participants in this study have shown their instructional leadership skills even if they have coordinators or principals under them. As early as April and May of 2020, these two school leaders spent many hours exchanging conversations with their principals/coordinators about the current pedagogical problems and solutions for the implementation of blended learning. They also encouraged their teachers to attend many webinars and explore different apps that would help them for their online classes. With the advent of technology, teachers can go beyond the usual lecture or discussion since research showed that there were still many teachers who used the conventional way of teaching that caused decreased motivation and less engagement of the students (Kirkup, Schagen, Wheater, Morrison \& Whetton, 2007; Nentwig, Parchmann, Grasel, Ralle \& Demuth, 2007; Wahono, 2011 as cited in Sunyono, 2018). Consequently, all these webinars would benefit the teachers in creating a learning environment that will increase the student motivation and academic performances (Oksuz, 2015).

Therefore, these school leaders have shown a role model in improving teachers' instructional skills that creates a continuous culture of professional growth and learning. Trainings bring a lot of beneficial results such as job satisfaction, organizational, commitment, improved employee skills, and productivity (Hughey \& Mussnug, 1997 as cited in Masadeh, 2012).

As shown above, both school leaders have exercised their instructional leadership style with the pursuit of improving teachers' professional growth and academic learning, which require them to set an exemplary model in the pedagogical skills.

\subsection{THEME 3. Connecting with People}

Both school leaders realized that networking with other leaders is critically important in the first quarter of this pandemic year (2020), as nobody has ever thought that such a crisis would change the education system drastically. They knew that making connections would help them in soliciting ideas and suggestions regarding blended learning. These are their statements: 


\section{Participant 1}

In such a pandemic time, network with other school leaders has become very helpful in giving some tips and ideas on how to go about the online class for the new normal. There were some schools as early as May that were able to come up with their Primer for the SY 2020-2021 with all the Do's and Don'ts for parents to understand better about the online class. These were indeed very helpful, and we were able to get and adopt some of their policies in our own institution. We need to build a strong connection with your people not just within the institution but also outside your institution.

Participant 2

I got in touch with a school leader... because when the lockdown happened, they had already shifted to the August school calendar. I asked him about the number of hours being used for synchronous and how many for the asynchronous. He was very helpful, he gave me a lot of tips, and he shared with me all the information. Aside from that, I called up my niece who is in Canada because they also had online learning at that time...I received the same answer that it is impossible to have a whole day of online teaching. These data were very helpful. No man is an island! It is really important to know people in the same industry.

Through collaboration with other school leaders, it brings a lot of benefits to complete one's vital tasks such as coordination with staff, allocation of resources, and delegation of tasks. In this rapidly changing time, there should be a professional environment for knowledge sharing, dissemination of best practices among the professionals, and policymakers which will make them effective leaders (Pont, Nusche \& Moorman, 2008). The purpose of this collaboration is to share information and best practices for continuous improvement (Stroud, 2010). This is one way of benchmarking which can greatly enhance an organization's performance by discovering the tools and technologies. Thus, this is achieved by providing numerous indicators on where we are now and where we are heading, and also improving our ability to realize our goals (Stroud, 2010). According to Garg and Ma (2005), as cited in Singh (2010), benchmarking leadership style is essential in improving the organizational performance by looking into different organizations and adapts their outstanding practices in the systems of technology, management, leadership, and styles.

As shown above, both participants have shown their benchmarking leadership style which they believed that building collaboration with other school leaders became very helpful on how to start with the planning stage. Eventually, it paved the way to finish the whole process of the implementation of blended learning for this school year. 


\subsection{THEME 4. Distributing the Tasks}

Many school leaders perform both micro and macro tasks in their respective organizations. With such immense responsibilities, how can they survive and sustain their passion and strength? Interestingly, both participants in this study have shown their leadership skills in distributing the tasks to be more efficient and effective. These are revealed in their long discourse:

Participant 1

Most of the time, I used Viber to communicate with the coordinators of Preschool, Elementary, and High School departments. It is a simultaneous job of communicating with these coordinators at the same time with the admin office head regarding the plan for online enrolment... As early as April and May, the decision for the online class was made known to department coordinators. Therefore, their tasks were given in terms of the class schedules, how many days of synchronous and asynchronous classes were made, teachers' loads, core subjects to teach, etc.

Participant 2

We divided the responsibilities among ourselves. My ECE coordinator is very good with graphics, so I requested her to prepare announcements to inform the parents about the enrolment. I requested the principal to create a private Facebook account to enroll all the parents and the students so that it would be easier to communicate with them. Then for the cashiers, we came up with a system should in case the parents go there and enroll or even if they did enroll online. For accounting department, she created an online system on the payment of tuition fees so that parents don't need to go the school, as they could just pay online.

It was explicitly shown through the long discourse of both participants that they knew their people very well, and delegate their tasks according to their talents, skills, and expertise. They mobilized their teams to create more opportunities for change, to strengthen their skills and talents for improvement (Hargreaves, Boyle \& Harris, 2014; Shava \& Tlou, 2018), and to make the work easier and faster in such a limited time. Trust and empowerment are two essential ingredients in creating a successful organization where team members would feel their individual worth and commitment to the organization. Both participants demonstrated their good listening skills and cared about the inputs of everyone in their team members.

With such leadership practices, both participants have applied Distributed Leadership Theory, a theory coined by Edwin Hutchins in the early 1990s in their organization where controlling and commanding management system is no longer effective. Rather, they used shared leadership practices in the school according to their expertise (Shava \& Tlou, 2018; Dampson, Havor \& Laryea, 2018). This type of leadership allows the 
organization to maximize its potentials and expertise in a more democratic manner (Dampson et al., 2018). However, this type of leadership is not something done by just an individual to others. Effective leader must have the skill to work well with his followers to achieve the organizational goals as they adapt to the changing times and demands in this complex world (Nahavandi, 2009 as cited in Asaari, Dwivedi, Lawton \& Desa, 2016). In sum, leadership should not be solely done by one heroic individual, but a collaborative work of every individual in an organization.

Overall, the findings revealed that these two Chinese private school leaders have encountered different issues and challenges during this pandemic in preparation for the opening of the school year 2020-2021. Amidst the crisis, they have exhibited their excellent leadership practices and styles such as situational leadership, instructional leadership, benchmarking leadership, and distributed leadership successfully in their respective institutions as they went through the process of restructuring the teaching and learning in the new normal. These leadership practices allowed them to thrive during this pandemic because they were able to adapt to the current change, build-up their core people, connect with other school leaders from different institutions, and distribute the tasks well to maximize the potential and expertise of the people in their institutions.

\section{Conclusion}

In navigating the education reforms out of necessity in the new normal, the two Chinese private school leaders in basic education have shown their exemplary leadership models and practices to meet the demands and challenges of the various stakeholders. School leaders need to understand leadership style that acknowledges the democracy and delegation of tasks to empower and utilize the potentials of the people within the organization. Thus, the adaptability of different changing roles and leadership practices depending on its situations are the essential qualities of school leaders to rise above the circumstances, and thrive in the crisis during and after the COVID-19 pandemic.

\section{References:}

1. Asaari, M. H. A. H., Dwivedi, A., Lawton, A. \& Desa, N. M. (2016). Academic leadership and organizational commitment in public universities of Malaysia. European Scientific Journal, 12(16).

2. Armfield, S. W. (2007). A descriptive case study of teaching and learning in an innovative middle school program. North Zeeb Road, Michigan; Pro-Quest Information \& Learning Company.

3. Athapaththu, H. K. S. H. (2016). An overview of strategic management: An analysis of the concepts and the importance of 
strategic management. International Journal of Scientific and Research Publications, 6(2), 124-127.

4. Baptiste, M. (2019). No teacher left behind: the impact of principal leadership styles on teacher job satisfaction and student success. Journal of International education and leadership, 9(1), 1.

5. Baxter, P. \& Jack, S. (2008). Qualitative case study methodology: study design and implementation for novice researchers e qualitative report, 13 (4), 544-559. Retrieved from hEp. nsuworks. nova. edu/tqr/voll3/iss $4 / 2$.

6. Connelly, L. M. (2014). Ethical considerations in research studies. Medsurg Nursing, 23(1), 54-56.

7. Connelly, L. M. (2016). Trustworthiness in qualitative research. Medsurg Nursing, 25(6), 435.

8. Cruz, C. D. P., Villena, D. K., Navarro, E. V., Belecina, R. R. \& Garvida, M. D. (2016). Towards enhancing the managerial performance of school heads. International Review of Management and Business Research, 5(2), 705-714.

9. Cypress, B. S. (2017). Rigor or reliability and validity in qualitative research: Perspectives, strategies, reconceptualization, and recommendations. Dimensions of Critical Care Nursing, 36(4), 253263.

10. Dampson, D. G., Havor, F. M. \& Laryea, P. (2018). Distributed Leadership an Instrument for School Improvement; The Study of Public Senior High Schools in Ghana. Journal of Education and eLearning Research, 5(2), 79-85.

11. Darishah, P., Daud, Y. \& Omar, F. M. S. (2017). Teaching and learning supervision by school management, attitude of teachers and competency of teaching. International Journal of Development and Sustainability, 6(10), 1367-1381.

12. Day, C. \& Sammons, P. (2013). Successful leadership: A review of the international literature. CfBT Education Trust. 60 Queens Road, Reading, RG1 4BS, England.

13. Delahunty, J. (2018). Connecting to learn, learning to connect: Thinking together in asynchronous forum discussion. Linguistics and Education, 46, 12-22.

14. Duffy, F. M. (2017). Reimagining Instructional Supervision: Supervising Knowledge Work. Rowman \& Littlefield.

15. Etikan, I., Musa, S. A. \& Alkassim, R. S. (2016). Comparison of convenience sampling and purposive sampling. American Journal of Theoretical and Applied Statistics, 5(1), 1-4. 
16. Fernandez, A. A. \& Shaw, G. P. (2020). Academic leadership in a time of crisis: The Coronavirus and COVID-19. Journal of Leadership Studies, 14(1), 39-45.

17. Glen, S. (June 12, 2015). Case Studies: Case Study Definition and Steps. StatisticsHowTo.com: Elementary Statistics for the rest of us! https://www.statisticshowto.com/case-studies/

18. Hargreaves, A., Boyle, A. \& Harris, A. (2014). Uplifting leadership: How organizations, teams, and communities raise performance. John Wiley \& Sons.

19. Harrison, H., Birks, M., Franklin, R. \& Mills, J. (January, 2017). Case study research: Foundations and methodological orientations. In Forum Qualitative Sozialforschung/Forum: Qualitative Social Research, 18(1).

20. Hechanova, M. R. M., Caringal-Go, J. F. \& Magsaysay, J. F. (2018). Implicit change leadership, change management, and affective commitment to change: Comparing academic institutions vs business enterprises. Leadership \& Organization Development Journal, 39, 914-925

21. Hussin, S. \& Al Abri, S. (2015). Professional development needs of school principals in the context of educational reform. International Journal of Educational Administration and Policy Studies, 7(4), 9097.

22. Ishak, N. M., Bakar, A. \& Yazid, A. (2014). Developing sampling frame for case study: Challenges and Conditions. World Journal of Education, 4(3), 29-35.

23. Laila, A. (2015). The effective school: The role of the leaders in school effectiveness. Educational Research and Reviews, 10(6), 695-721.

24. Litz, D. (2011). Globalization and the changing face of educational leadership: Current trends and emerging dilemmas. International Education Studies, 4(3), 47-61.

25. Lunenburg, F. C. \& Lunenburg, M. R. (2013). Convergent roles of the school principal: Leadership, managerial, and curriculuminstructional. International journal of education, 1(1), 1-9.

26. Lynch, B. (2015). Partnering for performance in situational leadership: a person-centred leadership approach. International Practice Development Journal, 5.

27. Masadeh, M. (2012). Training, education, development, and learning: what is the difference? European scientific journal, 8(10).

28. McCleskey, J. A. (2014). Situational, transformational, transactional leadership, and leadership development. Journal of business studies quarterly, 5(4), 117. 
29. Nanjundeswaraswamy, T. S. \& Swamy, D. R. (2014). Leadership styles. Advances in management, 7(2), 57.

30. Netolicky, D. M. (2020). School leadership during a pandemic: navigating tensions. Journal of Professional Capital and Community.

31. Pasia, A. J. (2019). Educational Leadership Strategies to Facilitate a School Transition into The Philippine K To 12 Basic Education Curriculum. International Journal of Education and Research, 7(7).

32. Pezalla, A. E., Pettigrew, J. \& Miller-Day, M. (2012). Researching the researcher-as-instrument: An exercise in interviewer selfreflexivity. Qualitative research, 12(2), 165-185.

33. Pont, B., Nusche, D. \& Moorman, H. (2018). Improving School Leadership, Volume 1 Policy and Practice.

34. Shanks, G. \& Bekmamedova, N. (2018). Case study research in information systems.

35. Shava, G. N. \& Tlou, F. N. (2018). Distributed Leadership in Education, Contemporary Issues in Educational Leadership. African Educational Research Journal, 6(4), 279-287.

36. Shoaib, S. \& Mujtaba, B. G. (2016). Use it or lose it: Prudently using case study as a research and educational strategy. American Journal of Education and Learning, 1(2), 83-93.

37. Singh, S. K. (2010). Benchmarking leadership styles for organizational learning in Indian context. Benchmarking: An International Journal, 17 (1), 95-114.

38. Skordis-Worrall, J., Haghparast-Bidgoli, H., Batura, N. \& Hughes, J. (2015). Learning online: A case study exploring student perceptions and experience of a course in economic evaluation. International Journal of Teaching and Learning in Higher Education, 27(3), 413422.

39. Stroud, J. D. (2010). Understanding the purpose and use of benchmarking. Isixsigma. February, 26.

40. Toure, A. \& Guoxin, Z. (2016). An investigation study between two genders, public and private schools, through the achievement of the pupils in the exact sciences: A case study of selected secondary schools in Conakry, Guinea. European Scientific Journal, 12(1).

41. United Nations Educational, Scientific and Cultural Organization (UNESCO, 2016). Global education monitoring report summary 2016: education for people and planet: creating sustainable futures for all.

42. Wilson, N. L. (2012). The principal's role in developing the classroom management skills of the novice elementary teacher. [Doctoral Dissertation, University of Tennessee].

43. Xu, M. A. \& Storr, G. B. (2012). Learning the concept of researcher as instrument in qualitative research. Qualitative Report, 17, 42. 
44. Yang, S. (November, 2014). Several thoughts on current Chinese education in the Philippines. In International Conference on Education Technology and Social Sciences. https://down load. atlantis-press. com/article/14695. pdf.

45. Yazan, B. (2015). Three approaches to case study methods in education: Yin, Merriam \& Stake. The qualitative report, 20(2), 134152.

46. Yin, R. K. (2009). How to do better case studies. The SAGE handbook of applied social research methods, 2(254-282).

47. Yukl, G. \& Mahsud, R. (2010). Why flexible and adaptive leadership is essential. Consulting Psychology Journal: practice and research, 62(2), 81.

48. Zainal, Z. (2007). Case study as a research method. Jurnal kemanusiaan, 5(1).

49. Zepeda, S. J. (2012). Professional development: What works. Eye on education. Journal of Educational Administration, 51(5), 728-730.

50. Zhang, G., Bohley, K. A. \& Wheeler, L. (2017). Global perspective and the implications for school leadership. Journal of Academic Administration in Higher Education, 13(2), 9-14. 